\title{
Ė POSSÍVEL A EXISTÊNCIA DE SISTEMAS REGIONAIS DE INOVAÇÃO EM PAÍSES SUBDESENVOLVIDOS? ${ }^{1}$
}

\author{
Cássio Rolim²
}

\section{INTRODUÇÃO}

A ênfase colocada nas inovações como a responsável pela diferenciação das economias nacionais e regionais ocupa um espaço cada vez mais amplo na literatura econômica. Os mais variados enfoques as colocam como peça fundamental em suas elaborações analíticas. Ela está presente na discussão dos sistemas nacionais de inovação, na chamada economia evolucionista (LUNDVALL, 1992), na discussão dos clusters industriais (PORTER, 1990), na perspectiva dos economistas da teoria da regulação (AMABLE et al., 1997), na dos autores que trabalharam com os distritos industriais (BECATTINI, 1991) e até mesmo na de autores da economia neoclássica (ROMER, 1990).

Como a maior parte dessa literatura enfatiza a importância dos aspectos territorializados da problemática, também os autores e os responsáveis pelas políticas regionais têm se debruçado sobre essa temática com vigor e esperanças só comparáveis aos empenhados quando as respostas para os problemas regionais pareciam ser dadas pela teoria da polarização.

Essas mesmas esperanças, uma vez mais, despertaram o interesse daqueles que lidam com problemas de desenvolvimento em países subdesenvolvidos. Aqui também ocorre uma busca intensa de compreensão dos processos inovadores que poderiam contribuir para a superação desse estado de subdesenvolvimento. No entanto, existem certas características no funcionamento das economias subdesenvolvidas que colocam restrições

1 Uma versão foi apresentada no $6^{\text {th }}$ Regional Science Association International World Congress 2000, Lugano, Suíça.

${ }^{2}$ Professor titular do Departamento de Economia e professor do Programa de Pós-Graduação em Desenvolvimento Econômico da Universidade Federal do Paraná (PPGDE-UFPR). 
aos processos inovadores, inexistentes nas situações estudadas pelos autores dos países desenvolvidos. Neste texto, vamos discutir algumas delas e as implicações que trazem para o uso do conceito de Sistemas Regionais de Inovações.

O texto está dividido em quatro partes. Inicialmente será feita uma breve exposição sobre as alterações na base produtiva e suas implicações sobre os territórios, a seguir será feita uma síntese do conceito de Sistema Regional de Inovação, subdividida em três partes, considerando suas raízes teóricas e o conceito propriamente dito. Na terceira parte será apresentado o caso do estado do Paraná, no Brasil, e dentro dele, a experiência específica de uma empresa considerada modelo no que se refere à inovação tecnológica e interação com as organizações educacionais paranaenses: a Siemens/Equitel. A última parte traz as considerações finais sobre o tema.

\section{REESTRUTURAÇÃO TECNOLÓGICA E TERRITÓRIOS ${ }^{3}$}

A abertura dos mercados transformou profundamente as maneiras de produzir e de comercializar afastando-as dos paradigmas de produção de massa. Essa transformação tem várias formas, qualificando de maneira diferenciada as relações da economia com os territórios. O território é agora visto como matriz de organização e de interações sociais e não mais como estoque ou reunião de recursos técnicos. Essas mudanças estão no centro das novas configurações espaciais e, particularmente, da pujança das metrópoles.

As empresas, na medida em que participam de uma competição mundial, têm que enfrentar uma equação muito difícil para sobreviver. Dado o barateamento relativo dos custos de transporte, se por um lado fica mais fácil o acesso a mercados distantes, por outro, aquele mercado próximo, cativo da empresa, fica mais vulnerável à concorrência. Assim, para atender a mercados com diferenciações decorrentes inclusive de padrões culturais, a empresa terá que ser capaz de produzir com custos reduzidos, qualidade elevada, variabilidade de produtos, grande capacidade de reação às mudanças detectadas na demanda e sobretudo ter uma grande capacidade de inovação.

A sua performance é permanentemente testada segundo a equação a seguir:

${ }^{3}$ Esta parte baseia-se fundamentalmente em Veltz (1996). 


\section{Performance $=$ Custo $\downarrow+$ Qualidade $\uparrow+$ Variedade + Capacidade de Reação + Inovação}

Em uma organização clássica, esses elementos são em grande parte contraditórios entre si. Nessas organizações, orientadas pelos principios administrativos que denominaremos tayloristas, cada setor é especializado na produção ou na realização de uma determinada tarefa. Também é um pressuposto a existência de economias de escala, ou seja, maiores unidades de produção produzirão a custos menores.

Contrapondo a essa organização, podemos falar de um sistema de produção denominado toyotismo, no qual mais importante que a especialização em determinada tarefa segmentada é a passagem coordenada de uma tarefa para outra, de tal forma que se tenha garantida a eficácia no conjunto do processo produtivo.

Esses dois sistemas, na realidade, não retratam fielmente nenhuma empresa concreta. É mais provável que as empresas do mundo real situem-se em algum ponto intermediário entre essas caricaturas extremas que desenvolvemos. Até porque os pontos em comum entre eles são muito maiores do que normalmente se imagina. (ZARIFIAN, 1993) No entanto, pode-se dizer que cada vez mais a tendência é a atividade econômica organizar-se dentro desses padrões de produção mais "flexíveis".

Assim sendo, a performance global/total dependerá cada vez mais das interações dos sistemas internos (setor de estudos, marketing, produção, finanças, manutenção, etc.) e dos externos às firmas (clientes, fornecedores, centros de pesquisa, concorrentes, etc.).

Em suma, a passagem para uma nova forma de concorrência impõe mudanças nos processos de organização tanto para as grandes como para as pequenas empresas. $\mathrm{Na}$ essência dessas mudanças está a descoberta de que a eficiência produtiva está fundamentalmente nas diferentes formas de cooperação entre as empresas.

Esta cooperação, por sua vez, é difícil de ser programada e rotinizada. É em torno desses processos de cooperação que a produção passa a ser organizada.

Assim sendo, o problema localizacional deixa de ser uma questão de relacionamento direto entre fatores, recursos e atividades produtivas. Ele agora é subordinado à questão mais geral das relações entre as estruturas sociais que permitem a cooperação e as formas espaciais.

Os elementos importantes para essa cooperação estão relacionados à geração de economias externas, pecuniárias e tecnológicas, presentes em estruturas semelhantes às apontadas por Marshall, os chamados distri- 
tos industriais, onde se encontrariam: a concentração em determinadas áreas de bens coletivos e de infra-estrutura social e material; um fundo comum de conhecimentos e valores que, aliados à educação formal, elevam o nível técnico e cultural da mão-de-obra; as redes de relações, que não aquelas do mercado existente entre os empresários, a circulação de conhecimentos formais e informais que essas redes permitem.

A geografia da eficácia produtiva é cada vez menos uma geografia de custos e passa a ser cada vez mais uma geografia da organização. A atratividade de um território ou de uma região, dessa forma, está vinculada à capacidade que ele tem de gerar esses elementos.

Tais elementos, por sua vez, estão relacionados com complexos fenômenos culturais, onde a interação sistemática entre pessoas, organizações públicas e privadas, irá propiciar o aparecimento de inovações, organizativas e tecnológicas, que se encontram na raiz do desenvolvimento regional. Esse é o assunto das próximas páginas.

\section{SISTEMA REGIONAL DE INOVAÇÃO}

O referencial teórico para este conceito pode ser encontrado principalmente nos trabalhos de Cooke e seus parceiros (1997, 1998a e 1998b). Segundo o autor, as primeiras referências ao termo surgiram no início dos anos 90 e a sua evolução tem origem em duas grandes vertentes teóricas. Uma primeira com origens nos trabalhos sobre inovação tecnológica, particularmente aqueles referentes aos Sistemas Nacionais de Inovação (LUNDVALL, 1992) e a outra decorrente dos avanços nas teorias de desenvolvimento regional.

\section{Sistema Nacional de Inovação}

A discussão sobre os Sistemas Nacionais de Inovação (SNI) enfatiza a importância das inovações sobre os processos de desenvolvimento econômico dos países. Essas inovações resultam da interação entre firmas, clientes, instituições de pesquisa e de governo, constituindo um ambiente propício ao aprendizado de novas maneiras de produzir e organizar a produção. Uma das questões mais enfatizadas são os processos pelos quais se dá esse aprendizado e os papéis desempenhados pelos diferentes atores envolvidos. 
A idéia de inovação presente nesses trabalhos é vista num sentido amplo. Ela vai além de novas descobertas em atividades e produtos na fronteira do progresso tecnológico. Ela também refere-se às alterações na produção de produtos menos elaborados, nos comportamentos, na própria mudança de valores culturais e hábitos rotineiros.

\begin{abstract}
Mudança tecnológica, num sentido amplo, vai além do mero progresso técnico; ela também implica em alterações na organização, comportamentos, e na maneira pela qual os diferentes agentes de um sistema se relacionam entre si, etc....Da mesma forma que difusão de tecnologias requer mudanças paralelas na organização do trabalho e da produção, a mudança técnica também é possível se for acompanhada por mudanças culturais ou alterações de hábitos e rotinas (COOKE et al., 1997 p. 478, )
\end{abstract}

Essas mudanças, no entanto, têm que ocorrer de uma forma sistêmica, o que implica em interações continuadas entre os atores. Interações estas que, enquanto processo social, devem ser contínuas ao longo do processo de geração da inovação, na medida em que este envolve o desenvolvimento de conhecimentos, a sua difusão e disponibilidade. Isto implica também em um grau de abertura e de confiança elevado nesses relacionamentos, ainda que em determinados momentos essa abertura e confiança venham a sofrer algumas restrições ao tratar de algumas informações confidenciais.

Assim sendo, se enquanto processo social as inovações dependem de uma elevada interação entre os atores, uma dimensão crucial em toda a sua trajetória passará a ser o grau de confiabilidade nos participantes. A outra dimensão, também de importância fundamental, é aquela relativa às formas pelas quais ocorre o aprendizado dentro do sistema. Esses pontos voltarão a ser debatidos mais adiante.

Pode-se então dizer, como Metcalfe (1995, p. 38) que:

Um sistema nacional de inovação é aquele conjunto de diferentes instituições que, em conjunto e individualmente, contribuem para o desenvolvimento e difusão de novas tecnologias e que fornecem a estrutura dentro da qual pode-se formular e implementar políticas para influenciar o processo de inovação. Como tal é um sistema de instituições interligadas para criar, armazenar e transferir o conhecimento, habilidades e artefactos que definem novas tecnologias. 
No entanto, segundo os autores, existem vários elementos que indicam que as questões tratadas nessa discussão podem ser melhor compreendidas se analisadas em um âmbito territorial mais restrito, como o regional.

Aqui entra em cena o segundo elemento formador do conceito de SRI: a região.

\section{Região, regionalismo}

Dentro da análise regional, o conceito de região já foi apresentado com diferentes conteúdos. Na economia regional, os esforços de Boudeville (1972) conseguiram conceituá-la na perspectiva da polarização, do planejamento e da homogeneidade. Essa conceituação é a base das principais técnicas de regionalização ainda hoje utilizadas. No entanto, elas refletem o mainstream da época sobre desenvolvimento regional caracterizado por políticas de "cima para baixo", do nacional para o local, e por investimentos em grandes projetos que buscavam a constituição dos "polos de desenvolvimento". ( BOISIER, 1989).

Essa regionalização, a partir do nível nacional, que muitas vezes redundava em redefinições político-administrativas, raramente contemplava os fenômenos, denominados, em um sentido amplo, de regionalismo. Ou seja, a determinações de regiões dentro de um processo histórico, baseado em experiências culturais, econômicas e de lutas comuns. Vários autores retomaram esse aspecto das questões regionais ainda nos anos oitenta. Entre eles, Coraggio (1980) e Markusen (1987).

Essa perspectiva, documentada em intensa literatura no final dos anos oitenta e ao longo da década de 90 , é a mais interessante para a discussão dos SRI.

A região passa a ser vista como resultante de um processo de construção onde uma determinada sociedade, interagindo com o meio natural, constrói um particular subsistema social. Ela deixa de ser vista apenas como um território habitado para passar a ser entendida como um espaço social. O corolário dessa perspectiva é que nem todos os territórios habitados podem ser considerados regiões. Somente aqueles espaços geográficos que consigam também ser espaços sociais poderão ser considerados regiões.

Região, nesse sentido, passa a constituir-se numa

...matriz de grupos sociais cujo nexo de articulação seja dado pela consciência coletiva de pertencer a um território comum que, formando parte de um território nacional, possui suficientes especificações (recursos, cultura, paisagem, etnia,etc.) para 
diferenciar-se em tudo, e cujos interesses fracionais ou de classe estejam subordinados estruturalmente a um interesse coletivo regional, expresso em reais projetos políticos, tanto de caráter permanente como transitório. (BOISIER, 1989, p. 595)

Nesse processo de construção da região (BOISIER, 1992) certos elementos vão sendo estabelecidos, formando um microcosmo, que a diferencia dos demais territórios e também do nível agregado nacional, onde regras comuns de relacionamento passam a ser aceitas, estabelecem-se instituições diferenciadoras, sob as quais são constituídas as organizações locais, enfim é constituído aquilo que Putnam (1992), chamou de capital social e que também pode ser visto como a construção de uma ordem social coletiva, com o estabelecimento de um processo de regulação microconstitucional, que estabelece as rotinas institucionais, normas e valores que irão permear as organizações que os articulam. (COOKE; MORGAN, 1998.)

Esta perspectiva já impõe restrições ao surgimento de SRIs. Nem todos os territórios habitados conseguem tornar-se uma região. Conseqüentemente, nem todos conseguirão montar sistemas que permitam a geração de inovações e nem todos conseguirão tornar-se competitivos. Assim como poucas localidades têm um distrito industrial, poucas regiões reúnem condições para ter um SRI. (COOKE et al., 1998b)

\section{Inovação}

\section{Sistemas regionais de aprendizado e Sistemas Regionais de}

A partir das discussões sobre os sistemas nacionais de inovação e sobre o regionalismo no desenvolvimento regional, os autores caminham para a construção do conceito de sistemas regionais de inovação. Antes, porém, aprofundam a discussão sobre os processos pelos quais ocorre o aprendizado (learning).

Para eles, o aprendizado (learning) significa uma mudança na capacitação de uma pessoa ou de uma organização. Isso porque esse aprendizado não é apenas visto como um acréscimo de informações, mas sim, visto na perspectiva piagetiana, na qual ele ocorre num processo de interação entre o que sabemos sobre uma determinada situação e o que podemos perceber como novo nessa situação. Em decorrência, é possível distinguir, em termos de formação do conhecimento, dois níveis de aprendizado. $\mathrm{O}$ primeiro seria aquele que fornece a competência (competence), ou seja, habi- 
lidade para realizar uma tarefa específica, e um segundo que traz a capacitação (capability), que é a compreensão dos mecanismos subjacentes à solução do problema envolvido na tarefa. ( COOKE; MORGAN, 1998).

Evidentemente um sistema de aprendizado que capacite é bem mais oneroso que um onde apenas se forneça competências. Em decorrência, um sistema regional de aprendizado eficiente não poderá restringir-se simplesmente a uma transferência de competências de outras partes. Mesmo porque as experiências não se repetem.

Na perspectiva do desenvolvimento econômico, não se pode imaginar que todo esse arcabouço para aumentar a capacitação dos países/ regiões possa prescindir de uma atuação intensa do Estado. (CARLEIAL, 1997) Assim sendo, os aparelhos de estado, nacionais ou regionais, terão que desenvolver uma infra-estrutura que viabilize esse sistema de aprendizagem, composta por agências de desenvolvimento, organizações de treinamento, escritórios sub-regionais, etc.

$\mathrm{Na}$ medida em que esse sistema regional de aprendizado interaja, formal ou informalmente, com universidades, institutos de pesquisa, agências de treinamento vocacional, transferência de tecnologia, parques tecnológicos, assim como com as empresas em geral, ele tende a se transformar em um SRI. (COOKE; MORGAN, 1998)

Os autores acentuam as diferenças entre sistemas regionais de aprendizado e sistemas regionais de inovação. Isso porque o aprendizado é o ponto de partida para a inovação. Indo além, eles fazem uma distinção entre tutoramento (tutoring) e aprendizado (learning).

O tutoramento pode ser compreendido como o domínio de conhecimentos e da capacidade de iniciar inovações baseadas em interações upstream (próximas do ponto de origem da invenção ou da idéia) assim como naquelas mais downstream (próximas ao mercado). Essa distinção é importante porque nem todos os países e regiões irão conseguir dominar a fronteira tecnológica em muitos setores. $\mathrm{O}$ cenário mais provável para a maioria das economias regionais será a inovação downstream, isto é, aquela decorrente de interações mais próximas dos usuários e consumidores. Para essas, os autores acreditam que o sistema regional de aprendizado seja mais importante. Nesse ponto, os autores chegam ao atual estágio de desenvolvimento do conceito de SRI. Assim sendo,

As regiões que possuem o conjunto ideal de organizações para a inovação inseridas em um meio institucional adequado (Johnson and Gregersen, 1996; Maillat, 1995) onde ligações sistêmicas e comunicação interativa entre os atores da inovação é um fato 
normal, enquadram-se na designação de sistema regional de inovação. A expectativa é que esse conjunto de organizações seja constituído de universidades, laboratórios de pesquisa básica, laboratórios de pesquisa aplicada, agências de transferência de tecnologia, organizações regionais de governança, públicas e privadas, (p.ex., associações comerciais, câmeras de comércio), organizações de treinamento vocacional, bancos, empresários dispostos a desenvolver novos produtos em parcerias de risco, pequenas e grandes empresas interagindo. Além disso essas organizações devem demonstrar vínculos sistêmicos através de programas em comum, participação conjunta em pesquisa, fluxos de informações e pelo estabelecimento de linhas de ação política pelas organizações de governança. Esses são sistemas que combinam aprendizado com capacidade de inovação, "upstream" e "downstream", e que merecem, portanto, a designação de sistemas regionais de inovação. (COOKE; MORGAN, 1998, p. 71)

Pode-se ver nesta conceituação a existência de vários subsistemas correlatos na constituição de um SRI. Entre os mais importantes, encontram-se os subsistemas financeiros e de aprendizado e um outro subsistema, relacionado com uma cultura produtiva. Sem o primeiro, as possibilidades de inovação ficam muito reduzidas, particularmente para estruturas regionais em que predominem as pequenas e médias empresas. O sistema de aprendizado é fundamental. As restrições ao seu funcionamento significam restrições de acesso ao conhecimento acumulado e portanto à anulação da possibilidade de gerar algum tipo de inovação.(COOKE et al. 1997) Finalmente a cultura produtiva, que significa o grau de envolvimento local com as atividades que se desenrolam na região, o ambiente e as atitudes voltadas para essas atividades, decorrentes da existência de uma cultura técnica inerente aos habitantes da região, advinda da transmissão de conhecimentos e saberes, passados de pai para filho. É o que pode ser expresso pelos conceitos de milieu e milieu inovateur desenvolvidos no âmbito do Gremi ${ }^{4}$.(MAILLAT, 1994).

Na tabela 1 são apresentados dois perfis regionais caracterizando as estruturas administrativas e autonomias governamentais de cada uma delas. Eles representam estereótipos extremos e a maioria das regiões devem estar em uma posição intermediária a eles. No entanto, quanto mais próxima uma região estiver do perfil 1 , maior a probabilidade dela ter constituído um Sistema Regional de Inovação.(CoOKE et al., 1997):

${ }^{4}$ Groupe de Recherche Européen sur les Milieux Innovateurs 


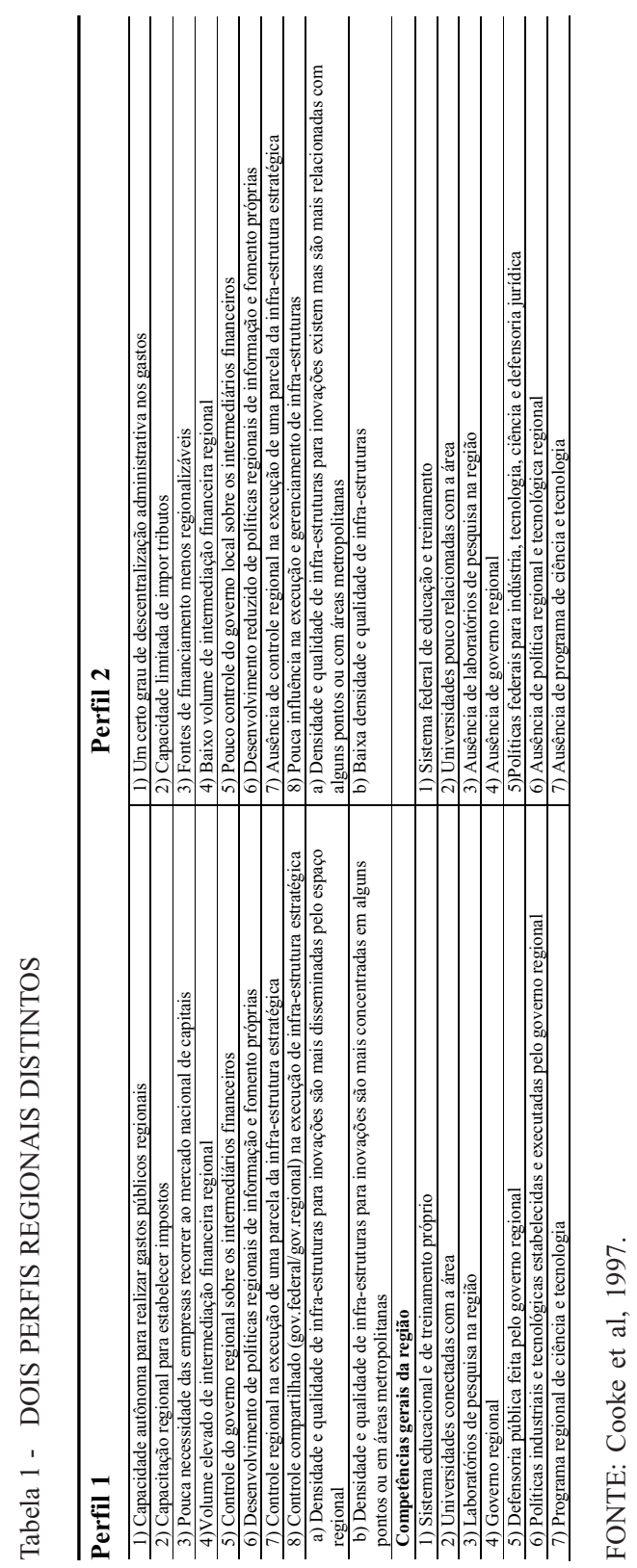




\section{O ESTADO DO PARANÁ}

O Brasil é uma república federativa com mais de 160 milhões de habitantes, um Produto Interno Bruto de cerca de 777 bilhões de dólares e um produto interno per capita em torno de 5 mil dólares. No entanto, apesar de estar entre as 10 maiores economias do mundo, possui um dos mais altos índices de concentração de renda. Dentro do seu território praticamente tudo é produzido. Do alfinete ao avião, passando pelo automóvel que já é produzido há cerca de 50 anos no país.

A industrialização do país data do início dos anos 30 , tendo sido intensificada a partir dos anos 50. Uma das suas características é ser extremamente concentrada no estado de São Paulo, particularmente em sua região metropolitana (cerca de 16 milhões de habitantes). No entanto, a partir dos anos 70, houve uma certa desconcentração das atividades econômicas no país que, embora incipiente, incorporou novos territórios e transformou a economia de várias regiões. Essa desconcentração, no entanto, passou a dar sinais de estancamento e há a possibilidade de uma certa reconcentração no estado de São Paulo. (GUimarães Neto, 1996)

O território que será estudado, o estado do Paraná, é um estado membro da federação, com $199.554 \mathrm{~km}^{2}$, equivalente a 2/3 da Itália, com uma população de cerca de 9 milhões de habitantes, tendo como capital Curitiba, cuja região metropolitana abriga cerca de 2 milhões de pessoas e está constituindo-se no espaço dos novos investimentos da indústria automobilística no Brasil.

O estado do Paraná tem uma história de povoamento recente. Desde os primórdios da colonização brasileira, no século XVI, apenas o litoral e, posteriormente, a parte onde hoje se encontra Curitiba, eram habitadas pelos colonizadores. A ocupação do norte do estado só foi ocorrer com intensidade a partir dos anos 40, em decorrência da cafeicultura paulista. Foi uma das áreas mais ricas do estado até um passado recente. $\mathrm{O}$ sudoeste foi ocupado a partir dos anos 50, também em decorrência de uma frente de ocupação vinda do Rio Grande do Sul, onde predominavam famílias praticando uma agricultura de subsistência.

Assim sendo, o estado foi povoado por três frentes de ocupação, vindas de diferentes partes do Brasil, cada uma em um momento histórico diferente. Isso foi um grande problema para as administrações estaduais, que muitas vezes tiveram que enfrentar tentativas de emancipação de parte do território. Ou seja, a maneira pela qual a ocupação foi feita tornou-se um 
elemento dificultador do surgimento de uma identificação com o território, do surgimento de uma identidade paranaense.

O estado sempre foi caracterizado como um estado agrícola, onde nos últimos 15 anos é praticada uma das agriculturas mais modernas do Brasil. Por outro lado, a sua capital, Curitiba, a partir dos anos setenta, começa a experimentar um processo de industrialização em que as indústrias tradicionais vinculadas à madeira e à produção de alimentos, começam a dar lugar aos gêneros mais modernos presentes na indústria brasileira, com produtos derivados dos grupos eletro-eletrônicos e metal-mecânicos. Essas novas indústrias, na sua maioria filiais de indústrias paulistas e multinacionais já instaladas no Brasil, resultavam da expansão de empresas localizadas na Região Metropolitana de São Paulo (RMSP), ou, como é o caso da Volvo no início dos anos setenta, e das demais indústrias automobilísticas dos anos noventa (Renault, Audi, Chrisler, etc.) eram investimentos novos em território brasileiro. Não obstante algumas vantagens localizacionais que a RMC possuía, o grande fator de atração para essas empresas sempre foram políticas extremamente generosas de incentivos fiscais.

\section{A estrutura produtiva do Paraná}

Entre 1985 e 1997, o PIB do Paraná passou de 5.96\% a 6.13\% do PIB brasileiro. Esse tem sido historicamente o percentual de participação do estado na economia nacional. As atividades em que o estado tem maior participação nos PIBs setoriais do Brasil são Agropecuária, Construção e Eletricidade, gás e água. Em termos de quociente localizacional, as atividades com $\mathrm{QL}>1$ são Agropecuária, Eletricidade, gás e água, Construção, Alojamento e alimentação, Transporte e armazenagem. Dentro da estrutura interna do estado, as atividades Agropecuárias tem uma queda de $23.88 \%$ para $14.04 \%$. A atividade industrial, na sua totalidade, tem um acréscimo modesto de $35.47 \%$ para $38.12 \%$, devido sobretudo à indústria da Construção. Porém, o maior crescimento veio do conjunto do setor Serviços que passou de $40.66 \%$ para $47.85 \%$.

A indústria de transformação do Paraná representa cerca de 5\% da indústria brasileira e, além disso, apenas três gêneros: Produtos alimentícios, Química e Madeira representavam mais de $50 \%$ da sua produção em 1985. Ao longo do período essa estrutura veio sendo modernizada. No entanto, em 1997, os principais gêneros ainda eram Produtos alimentícios e Química, vindo em terceiro lugar Mecânica e, em quarto, Madeira. O predomínio desses gêneros torna pouco visíveis as transformações que estão ocorrendo. Nos setores mais novos como Material elétrico, Mecânica, Ma- 
terial de transporte, etc. está surgindo a nova estrutura industrial do estado, porém, gradativamente tornando-se importante, eles ainda são obscurecidos pelos dois maiores gêneros.

Tabela 2 - PARTICIPAÇÃO DA REGIÃO NO PIB DO BRASIL, TOTAL E SETORIAL; PARTICIPAÇÃO DAS ATIVIDADES ECONÔMICAS NO PIB

\begin{tabular}{lcc|cccc}
\hline & $\mathbf{1 9 8 5}$ & $\mathbf{1 9 9 7}$ & \multicolumn{2}{c}{$\mathbf{1 9 8 5}$} & \multicolumn{2}{c}{$\mathbf{1 9 9 7}$} \\
\hline & $\mathbf{a}$ & $\mathbf{a}$ & $\mathbf{b}$ & $\mathbf{b}$ & $\mathbf{b}$ & $\mathbf{b}$ \\
& Paraná & Paraná & Brasil & Paraná & Brasil & $\begin{array}{c}\text { Paraná } \\
\text { Total }\end{array}$ \\
Agropecuária & $\mathbf{5 . 9 6}$ & $\mathbf{6 . 1 3}$ & $\mathbf{1 0 0 . 0}$ & $\mathbf{1 0 0 . 0}$ & $\mathbf{1 0 0 . 0}$ & $\mathbf{1 0 0 . 0}$ \\
Indústria extrativa mineral & 1.66 & 11.20 & 11.23 & 23.88 & 7.68 & 14.04 \\
Indústria de transformação & 0.19 & 0.14 & 3.27 & 0.10 & 1.04 & 0.02 \\
Eletricidade, gás e água & 5.01 & 4.98 & 32.33 & 27.18 & 23.48 & 19.09 \\
Construção & 4.57 & 8.55 & 2.63 & 2.02 & 3.52 & 4.92 \\
Comércio e reparação de veículos e de objetos & 6.61 & 8.84 & 5.56 & 6.17 & 9.76 & 14.09 \\
pessoais e de uso doméstico & & & & & & \\
Alojamento e alimentação & 5.91 & 5.70 & 8.94 & 8.87 & 7.87 & 7.33 \\
Transporte e armazenagem & 5.11 & 7.02 & 1.63 & 1.40 & 1.8 & 2.07 \\
Comunicações & 7.55 & 7.69 & 2.83 & 3.59 & 2.03 & 2.55 \\
Intermediação financeira & 4.63 & 5.57 & 0.96 & 0.75 & 2.01 & 1.83 \\
Atividades imobiliárias, aluguéis e serviços & 5.78 & 3.90 & 13.15 & 12.76 & 6.43 & 4.10 \\
prestados às empresas & & & & & & \\
Administração pública, defesa e seguridade social & 4.75 & 6.17 & 5.30 & 4.22 & 14.30 & 14.40 \\
Saúde e educação mercantis & 4.08 & 4.49 & 9.06 & 6.21 & 14.89 & 10.91 \\
Outros serviços coletivos, sociais e pessoais & 6.0 & 6.18 & 1.67 & 1.68 & 3.26 & 3.29 \\
Serviços domésticos & & & & & & \\
& 4.46 & 3.78 & 0.90 & 0.67 & 1.48 & 0.91 \\
& 5.68 & 6.42 & 0.54 & 0.51 & 0.44 & 0.46 \\
\hline
\end{tabular}

FONTE: dados brutos: IBGE (1999) Contas regionais do Brasil 1985-1997. $\mathrm{Na}$ realidade trata-se do valor adicionado bruto.

Esses gêneros, no entanto, tendem a localizar-se na Região Metropolitana de Curitiba, que abriga mais da metade da indústria paranaense e a maioria absoluta desses novos gêneros. A nova indústria do Paraná está surgindo na RMC em decorrência de um processo de expansão da indústria brasileira, incorporando novos territórios. (ROLIM, 1996)

\section{Os elementos do SRI do Paraná}

Com base na síntese teórica das sessões anteriores, serão apresentados alguns dos elementos que poderiam compor um SRI no Paraná.

\section{Subsistema financeiro}

Em nível regional, praticamente não existe um sistema financeiro que providencie suporte para os demais subsistemas. As atividades de inovação existentes por parte de empresas recebem apoio de instituições fede- 
rais, como é o caso da Financiadora Nacional de Projetos, FINEP e do Conselho Nacional de Pesquisa e Desenvolvimento Tecnológico, CNPQ.

Embora nos últimos dez anos conste da Constituição Estadual a existência de um Fundo Estadual para o Desenvolvimento Científico, devendo receber $2 \%$ das receitas tributárias, apenas recentemente ele foi regulamentado. As dificuldades estavam no peso relativamente pequeno que o governo do estado queria atribuir às instituições científicas locais. Ainda que este ponto não tenha sido satisfatoriamente resolvido, o fato da organização do gerenciamento desse fundo estar sendo iniciada, traz a expectativa de alguma esperança nesse setor.

Dentro de uma perspectiva ampliada e se forem considerados os gastos gerais do estado com as suas entidades de ensino superior e institutos de pesquisa, o estado chega a gastar cerca de $11 \%$ da sua receita tributária. (PASSOS, 1998)

\section{O milieu inovateur}

A identificação deste subsistema é uma tarefa muito difícil que não será tentada no âmbito deste artigo. No entanto, alguns elementos importantes para a sua constituição tem sido apontados há longo tempo na literatura. Eles estão relacionados com algum tipo de identificação regional (básica nos processos de regionalismo) e com a existência de um certo grau de especialização das atividades produtivas regionais. Geralmente são as atividades objeto dos estudos relativos à constituição dos chamados "clusters industriais".

Vários elementos dificultam a constituição de uma identidade "paranaense". Em primeiro lugar, o tamanho do estado, $199.554 \mathrm{~km}^{2}$, equivalente a $2 / 3$ da Itália e a mais de duas vezes o tamanho de Portugal. Em segundo lugar, o fato da maior parte do território estadual ter sido ocupado recentemente (pouco mais de meio século). Em terceiro, esse povoamento decorreu de pelo menos três frentes de ocupação, originadas em diferentes momentos e processos históricos. Finalmente, as transformações contemporâneas, que estão levando à constituição de dois grandes espaços econômicos. O espaço do Paraná do agrobusiness, dentro do universo das atividades agropecuárias e o espaço do Paraná urbano, no universo das atividades industriais nacionais. (ROLIM, 1996). É mais fácil encontrar algumas identificações locais, como por exemplo, a existente no sudoeste do estado (ROLIM, 1993), do que uma identidade geral "paranaense". 
Quanto à especialização regional, também são encontradas algumas dificuldades. Embora tenham representatividade reduzida na composição do PIB estadual, é mais fácil encontrar aqueles elementos do milieau inovateur nas atividades agropecuárias. Por outro lado, aquelas atividades industriais nas quais, no passado, existiu alguma especialização e expertise regional, estão diluídas em um universo industrial em que hoje predominam a indústria Química e a Mecânica. O grande peso da Química deve-se à localização de uma grande refinaria de petróleo da Petrobras na região metropolitana de Curitiba. Quanto ao gênero Mecânica e em menor proporção, Material de Transporte, deve-se a instalação recente de várias indústrias automobilísticas já dentro dos padrões mais modernos de organização industrial. Ou seja, são atividades exógenas à antiga base produtiva local. A indústria de Produtos alimentícios é uma das mais tradicionais do estado e, no entanto, trata-se de um aglomerado muito heterogêneo, onde coexistem empresas com diferentes graus de sofisticação tecnológica e integração. A indústria da Madeira, no passado, foi muito importante para o estado mas hoje se encontra decadente. É paradoxal que o setor onde poderiam ser encontrados elementos para o milieu inovateur seja um dos mais decadentes. Restam os setores das indústrias Metal-mecânicas e a de Material elétrico e de comunicações. Nestes dois pode-se encontrar um certo milieau inovateur, embora, principalmente no último, haja a predominância de grandes empresas estrangeiras.

Dadas todas essas restrições, é difícil falar de milieau inovateur nas atividades industriais do estado do Paraná. Provavelmente, no entanto, ele existe na esfera do agrobusiness.

\section{O subsistema de aprendizado}

Provavelmente este é o subsistema mais desenvolvido dentro do estado do Paraná. Existem cerca de 101 organizações vinculadas à Ciência e Tecnologia no estado do Paraná. Entre elas, 45 são de pesquisa, extensão e fomento, com caráter privado e público (pertencentes aos três níveis de governo). (PASSOS, 1998, p. 15). As outras 56 são instituições de ensino superior (entre elas sete universidades e o CEFET-PR, Centro Federal de Educação Tecnológica) totalizando 119.071 alunos. O governo estadual possui 16 organizações de ensino superior, totalizando 47.184 alunos (cinco universidades e 11 faculdades) e 15 outras de pesquisa, extensão, articulação e fomento.

No que se refere ao ensino superior, esses números devem ser relativizados. Dos cerca de 119 mil alunos, apenas 17\% estão em organiza- 
ções federais. Na estrutura educacional brasileira, elas são as principais realizadoras de pesquisas, são as que contam com maior proporção de professores qualificados e trabalhando em regime integral. As organizações privadas tendem, na sua maioria quase absoluta, a manter cursos que são meros repassadores de uma cultura livresca, sem pesquisa e com professores em regimes de dedicação parcial, geralmente atuando em áreas do conhecimento com menor sofisticação tecnológica. As organizações públicas, estaduais e municipais, encontram-se numa situação intermediária.

Essas organizações de ensino superior constituem a parte mais visível do sistema de aprendizado, aquela por onde transita o conhecimento codificado. No entanto, as demais organizações têm as mais variadas funções e tipos de vinculação, indo desde aquelas que desenvolvem pesquisa básica com alto conteúdo tecnológico, como as desenvolvidas no Simepar, Sistema meteorológico do Paraná, e as da rede paranaense de telemática, até aquelas que se encarregam de gerenciar projetos locais de incubadoras tecnológicas, como é o caso da Fundetec, Fundação de desenvolvimento tecnológico de Cascavel. Os vínculos que se estabelecem entre essas organizações também são muito variados. Existem aquelas que são puramente estatais, outras em que existe uma participação conjunta entre o governo estadual, federal e associações empresariais. Outras estão vinculadas às cooperativas agropecuárias. Existem ainda aquelas que se caracterizam como organizações não-governamentais, o caso do Citpar, Centro de integração de tecnologia do Paraná, sendo um dos mais importantes e atuantes. (PASsos, 1998)

A cooperação entre essas organizações sofre, no entanto, de um problema básico. Ela é, com raras exceções, reduzida e esporádica. Além disso, muito embora existam importantes interações com o empresariado, na sua grande maioria, essa interação fica muito mais ao nível das associações de classe empresariais, que propriamente ao nível das empresas. Por outro lado, o tipo de conhecimento que circula entre essas organizações, na sua grande maioria não é um conhecimento da fronteira tecnológica. O sistema sequer está preparado para reproduzir eficientemente o conhecimento codificado.

Existem, no entanto, outras formas de aprendizado apontadas na literatura como sendo as mais importantes para o desenvolvimento tecnológico das empresas, que é aquela em que as empresas, relacionandose entre si e com os demais elementos do sistema, vão interagindo na produção da inovação.

No que se refere aos perfis apresentados no quadro 1, o Paraná está mais próximo do primeiro que do segundo. Apesar disso, não se conse- 
gue vislumbrar a constituição de um SRI no estado. Na perspectiva dos três subsistemas componentes de um SRI, o financeiro praticamente não existe e do "milieu inovateur" apenas pode-se ter a expectativa da sua existência nas atividades Agropecuárias. O subsistema de aprendizado, apesar das boas perspectivas, ainda é precário.

Vejamos a seguir a experiência de uma das empresas mais importantes no estado do Paraná.

\section{O caso da Siemens/Equitel}

A Siemens/Equitel é uma das firmas internacionais localizadas no Paraná com maior destaque no que se refere à inovação tecnológica e interação com o sistema de aprendizado local.

A Siemens internacional foi fundada na Alemanha, em 1847, e está entre as cinco primeiras empresas de engenharia elétrica e eletrônica do mundo. Possui cerca de 305 fábricas na Europa, 142 nas Américas, 69 na região do Pacífico e 11 no resto do mundo. A empresa atua no Brasil desde o século XIX, tendo constituído a Siemens do Brasil em 1905. Atualmente, o grupo é constituído por quatro empresas: a Equitel (atualmente denominada Siemens Divisão de Telecomunicações) com $50 \%$ do faturamento líquido do grupo; a Siemens, com 37\%; a Osram, 7\% e a Icotron com 6\%. Essas empresas têm fábricas em várias partes do Brasil. Do extremo norte (Manaus, no Amazonas) ao extremo sul (Gravataí, no Rio Grande do Sul). Ela está no Paraná desde 1973, produzindo centrais telefônicas. Possui uma fábrica em Curitiba e recentemente instalou uma fábrica de componentes elétricos para automóveis que deverá abastecer várias das indústrias automobilísticas do Brasil e Argentina. (sCATOLIN et al., 1999).

A evolução tecnológica da sua unidade em Curitiba (Siemens/ Equitel) foi condicionada, como se verá mais adiante, por dois fatores institucionais. Em primeiro lugar, ela está acoplada à expansão da Telepar (Empresa telefônica do estado do Paraná) e em segundo, à política protecionista de informática do governo brasileiro. Segundo Scatolin et al., 1999, os esforços da empresa entre 1973 e 1978 buscavam a adaptação às normas locais e à nacionalização de componentes desenvolvidos no exterior. A partir de 1978, começa uma fase de desenvolvimento de produtos específicos para o mercado brasileiro. Em 1989, começam a ser desenvolvidos sistemas complexos para o sistema brasileiro, com base em tecnologia obtida do exterior. A partir de 1992, esses sistemas começam a ser produzidos para o mercado internacional. Após 1994, dentro de uma política mundial de implantação de centros de competência por parte da matriz alemã, a unidade de Curitiba 
tornou-se centro de competência mundial em diversas áreas, vinculadas a treinamento e desenvolvimento em telecomunicações.

A interação com os centros educacionais do estado sempre foi intensa. Ela reflete-se em convênios de treinamento de mão-de-obra, doação de laboratórios, desenvolvimento conjunto de sistemas e produtos, grande utilização de estagiários, etc. Entre 1994 e 1998, esses convênios com instituições paranaenses representaram cerca de 41,9 milhões de reais, ${ }^{5}$ que adicionando-se aos demais gastos com outras instituições de pesquisa espalhadas pelo Brasil, totaliza um gasto de 71,5 milhões de reais. Ou seja, quase $60 \%$ desses recursos foram utilizados no Paraná. Uma das razões desses investimentos está na formação de um potencial de mão-de-obra para a empresa e também de treinamento para uso de seus produtos. Entre os seus empregados, até $50 \%$ tem segundo grau completo e $34 \%$ curso universitário. Entre esses, $61 \%$ são engenheiros com especialização em engenharia elétrica e eletrônica. (sCATOLIN et al., 1999).

Essa trajetória de investimentos em tecnologia foi condicionada, como já foi dito, por dois grandes fatores. Em primeiro lugar a Telepar, empresa pública de telecomunicações do estado. O Paraná, por ser um estado de ocupação recente, tinha tudo por fazer em termos de telefonia. Assim sendo, praticamente todos os seus investimentos nessa área eram investimentos novos. O acoplamento entre a expansão da empresa e a Siemens/Equitel foi intenso. Muitos dos produtos foram desenvolvidos para atender à Telepar e a partir daí, atender as demais empresas de telecomunicações do Brasil. A Telepar era considerada a empresa modelo do Brasil. Dessa forma, a rede de telecomunicações do estado foi montada com equipamentos oriundos das tecnologias mais recentes.

Vinculado a este primeiro fator, está um conjunto de leis protecionistas, entre as quais a 8248/91, conhecida como a lei de informática, do mercado brasileiro que obrigavam as empresas do setor a manter um índice de componentes fabricados no Brasil de no mínimo $60 \%$, condição para obter crédito subsidiado dos bancos estatais de desenvolvimento. Além disso, puderam ter uma dedução de até 50\% do imposto de renda, entre 1992 e 1997, dos gastos em inovação tecnológica feitos no país, diretos ou por meio de convênios com centros de pesquisa e universidades. (SCATOLIN et al., 1999).

Scatolin et al., 1999, também apontam para um componente de custo importante na decisão de investir em pesquisa e desenvolvimento no Brasil. Trata-se dos custos reduzidos.

${ }^{5}$ Câmbio de 1 dólar americano correspondente a 1.74 reais. 
O custo por colaborador do sistema de Pesquisa e Desenvolvimento da Siemens no Brasil, considerando salários e infra-estrutura, é de DM 120000, por ano e por pessoa, enquanto que esse mesmo custo na Alemanha alcança o valor de DM 250000 (SCATOLIN et al., 1999)

Avaliar o papel da Siemens/Equitel no contexto de um SRI não é uma tarefa fácil. A aparência dos processos nos apresenta uma empresa que gera muitas inovações e que interage intensamente com o subsistema de aprendizado formal do estado. A impressão é a de uma empresa "entranhada" (embedded) no Paraná. Os convênios formais e as interações informais que se estabeleceram ao longo de todos esses anos entre os atores parecem confirmar a presença de alguns dos elementos (constantes do subsistema de aprendizado) necessários para a construção de um SRI, tal como diz a literatura resenhada na seção 2.

No entanto, indo além das aparências, existem alguns pontos não esclarecidos que colocam dúvidas sobre esse processo. O primeiro deles é quanto à natureza das inovações que a empresa desenvolveu. A maior parte delas são meras adaptações locais às obrigatoriedades impostas pela legislação, seja no que tange às normas de segurança, seja no que se refere aos índices de nacionalização. Também não é muito clara essa denominação que o grupo Siemens faz de centros de excelência em determinados produtos. Essa excelência decorre do saber fazer bem esses produtos ou de saber desenvolvê-los? Na terminologia empregada por Cooke, apresentada nas seções anteriores, esses centros têm competência ou capacitação? Tudo leva a crer que se trata mais do primeiro caso que do segundo.

$\mathrm{O}$ segundo ponto refere-se aos incentivos fiscais que a empresa recebe. É um volume muito elevado. Os 71,5 milhões de reais que a empresa do Paraná gastou nos convênios com centros de pesquisa e universidades entre 1994 e 1998, representaram de fato, quando se considera apenas a redução do imposto de renda, um desembolso equivalente a 4 milhões de dólares ${ }^{6}$ por ano. Além disso, grande parte desses gastos referem-se a equipamentos e à construção de laboratórios e redes de comunicação cujo objetivo é, em grande parte, viabilizar a comunicação entre as organizações de ensino e a própria Siemens. Isso torna os gastos efetivos em pesquisa e desenvolvimento relativamente baixos. É quase como se a empresa estivesse "terceirizando" parte das suas atividades. Quando se considera adicionalmente que os custos são cerca de $50 \%$ mais baixos no Brasil do que na

${ }^{6}$ Câmbio de 1 dólar por 1.74 reais. 
Alemanha, tem-se que os gastos em pesquisa e desenvolvimento são realmente baixos.

Esses incentivos acabam funcionando como a maneira da empresa financiar esses gastos e constituem-se num "subsistema de financiamento" ad hoc. Eles não são especificamente regionais, pois se referem à isenção de impostos federais. No entanto, são os mais importantes. Ainda em nível federal, a empresa pode beneficiar-se dos financiamentos específicos do Banco Nacional de Desenvolvimento Econômico, BNDES. A empresa também se beneficia de isenções estaduais e municipais (ela instalou-se na cidade industrial de Curitiba, CIC, o que significa receber uma série de vantagens). No entanto, além desses recursos serem de menor monta, eles estão disponíveis para qualquer tipo de empresa, investindo ou não em pesquisa e desenvolvimento. Como se vê, não há fortes indícios da existência de algo parecido com um subsistema regional de financiamento.

Gastar pouco ou muito, dentro da perspectiva que estamos considerando, não é a questão mais relevante. O fundamental é saber como esse conhecimento está sendo transmitido e quem é o maior beneficiário dele. Também aqui a tarefa não é fácil. Como grande parte desses convênios foi realizada com centros educacionais, é de se esperar que tenham influído na melhoria da qualidade do ensino, fazendo com que o grande número de estudantes que fizeram estágio na empresa tenha melhorado a qualificação da força de trabalho, etc. No entanto, novamente, não se consegue saber até que ponto essa melhoria não foi, mais uma vez, apenas uma formação de força de trabalho específica para a empresa.

Resta ainda a questão do milieu inovateur na região. Ao longo da sua trajetória no Paraná, a Siemens/Equitel foi gradativamente entranhando-se na economia local, particularmente na RMC. Não se pode dizer que tenha existido uma "cultura local" prévia voltada para as telecomunicações. No entanto, algo parecido com isso parece ter se estabelecido na RMC ao longo do período de atuação da empresa.

Existe, porém, um ponto importante, poucas vezes considerado pelos analistas locais, para explicar esse esboço de um milieu. Trata-se das relações desenvolvidas entre a Telepar e a Siemens/Equitel. A trajetória das duas empresas é semelhante e a interação entre elas foi intensa. Como já foi dito, por ser um estado de povoamento recente, quase toda a infra-estrutura paranaense é nova. A Telepar foi a grande cliente da Siemens e desse relacionamento pode ter surgido muitas das inovações feitas pela Siemens, assim como muita da mão-de-obra treinada por meio dos convênios por ela patrocinados era utilizada pela Telepar, o mesmo ocorrendo com relação àqueles estabelecidos por esta última. Por outro lado, a Telepar era constitu- 
ída por um corpo técnico de alto nível, com grande parte de seus engenheiros formados no Centro Tecnológico da Aeronáutica, CTA, centro de excelência nacional.

Assim, do encontro entre uma grande empresa multinacional e de uma grande empresa privada, integrante do sistema Telebras (antiga empresa holding das empresas de telefonia dos estados brasileiros) é estabelecido um intenso relacionamento, do tipo cliente-fornecedor, cujos reflexos provavelmente devem ter-se refletido nas relações estabelecidas pela Siemens com os centros de pesquisa e ensino, tanto no Brasil como nas demandas com os centros mantidos pela matriz internacional.

Contudo, a privatização recente da Telepar coloca um ponto de interrogação sobre o futuro desse relacionamento.

Complementando estas notas, seria importante frisar que mesmo sendo uma das empresas apontadas como a que obteve maior sucesso na interação com o sistema de aprendizado formal do Paraná, a Siemens realizou cerca de $40 \%$ dos seus gastos com instituições de ensino e pesquisa de outros estados. Grande parte dos recursos usados para esses gastos foram financiados com verbas federais, seja por renúncia fiscal, seja por crédito subsidiado pelo BNDES. Além disso, a sua grande parceira, a Telepar, embora fosse uma empresa pública do estado do Paraná, na realidade era parte de uma holding nacional. O governo do estado do Paraná nunca teve o total controle sobre a empresa. Por outro lado, as inovações realizadas eram em grande parte decorrentes da necessidade de fazer adaptações para atender as normas brasileiras.

\section{CONSIDERAÇÕES FINAIS}

A revisão da literatura sobre Sistemas Regionais de Inovação coloca como elemento chave para a competitividade das empresas de uma determinada região ou de um determinado país, a capacidade de inovação que elas possuem. Essa capacidade de inovação, por sua vez, vai depender do domínio de conhecimentos e habilidades que, dadas as suas complexidades, são cada vez mais fruto de um patrimônio coletivo. Dentro da perspectiva evolucionista, os elementos básicos para a compreensão dessa capacidade inovativa são a capacidade financeira, o aprendizado e a existência de uma cultura voltada para a produção. Esses elementos foram desenvolvidos inicialmente dentro da perspectiva de estados nacionais, no entanto eles apresentam algumas especificidades para o caso regional. Ela reside na hi- 
pótese dos elementos importantes para a constituição de um sistema nacional poderem ser encontrados de forma concentrada em determinadas regiões, caracterizando-se muito mais como uma especificidade dessas regiões do que propriamente como elementos nacionais.

A maioria dos estudos sobre o tema foram feitos em países desenvolvidos. A questão discutida neste texto, no entanto, foi sobre a possibilidade de tais sistemas poderem se constituir numa base regional em países notoriamente deficitários em instituições de ensino e pesquisa, com graves restrições financeiras e, como no caso brasileiro, com dimensões continentais.

Tomou-se como estudo de caso o estado do Paraná, no Brasil, que se encontra entre aqueles em melhor situação econômica na federação brasileira, onde está se localizando a nova indústria automobilística brasileira, e com um aparato formal de ciência e tecnologia razoavelmente desenvolvido. Dentre as empresas estabelecidas no estado, foi utilizado como exemplo o caso da Siemens/Equitel, considerada a empresa mais bem sucedida em termos de relacionamento com a estrutura formal de ciência e tecnologia do estado.

No entanto, mesmo para um estado com boas condições de desenvolvimento e no caso de uma empresa considerada bem sucedida, os resultados não são muito animadores quanto à possibilidade da existência de um SRI.

Em primeiro lugar, não existe um subsistema financeiro estadual. $\mathrm{O}$ que existe está vinculado ao governo federal sob a forma de renúncia fiscal e financiamentos a juros subsidiados.

Quanto ao espírito inovador e ao "entranhamento" da empresa na economia estadual, os resultados da análise são, na melhor das hipóteses, cautelosos. Para o caso específico da empresa considerada, a "cultura" foi desenvolvida após a sua implantação no estado. Além disso, ela contou com a existência de uma grande cliente, a empresa pública de telefonia do estado, que por sua vez, não pode ser caracterizada propriamente como regional, uma vez que grande parte de suas determinações seguia uma lógica nacional.

De uma maneira geral, esse milieu inovateur apenas existe no estado em alguns setores como na indústria da Madeira e nas atividades Agropecuárias. No entanto, no que se refere às atividades industriais, ele está mais presente exatamente nos setores mais arcaicos e que menos têm apresentado inovações. As indústrias mais modernas do estado são de instalação recente e em grande parte filiais de empresas internacionais. 
Quanto ao subsistema de aprendizado, embora ele seja razoavelmente desenvolvido, na parte formalizada, a falta de interações sistêmicas impede um funcionamento eficiente. $\mathrm{O}$ estado conta com um número relativamente elevado de instituições de ensino superior e de instituições de pesquisa, no entanto a interação entre elas e as empresas tende, em grande parte, a ser formal ou então ocorre com alguma intensidade em situações esporádicas.

No caso da Siemens, onde essa interação é profunda e sistemática, ela também tende a ocorrer com instituições de outras partes do país e também, obviamente, com o exterior, com a sua matriz.

Este trabalho procurou mostrar que mesmo dentro de um país que se encontra entre as dez maiores economias do mundo, uma subunidade territorial, com governo próprio, sistema educacional formal próprio, com um território equivalente a duas vezes o do Reino Unido e com uma população equivalente à de Portugal, não é possível encontrar-se algo parecido a um Sistema Regional de Inovações nos termos colocados pela literatura analisada. A temática é muito rica e promissora, no entanto é importante que sejam ampliados os estudos em países subdesenvolvidos para que possamos saber mais sobre as condicionantes da existência desses sistemas.

\section{RESUMO}

A ênfase colocada nas inovações como a responsável pela diferenciação das economias nacionais e regionais ocupa um espaço cada vez mais amplo na literatura econômica. Os mais variados enfoques as colocam como peça fundamental em suas elaborações analíticas. Ela está presente na discussão dos sistemas nacionais de inovação, na chamada economia evolucionista (LUNDVALL, 1992), na discussão dos clusters industriais (PORTER, 1990), na perspectiva dos economistas da teoria da regulação (AMABLE et al., 1997), na dos autores que trabalharam com os distritos industriais (BECATTINI, 1991) e até mesmo na de autores da economia neoclássica (ROMER, 1990). Como a maior parte dessa literatura enfatiza a importância dos aspectos territorializados da problemática, também os autores e os responsáveis pelas políticas regionais têm se debruçado sobre essa temática com vigor e esperanças só comparáveis aos empenhados quando as respostas para os problemas regionais pareciam ser dadas pela teoria da polarização. Essas mesmas esperanças, uma vez mais, despertaram o interesse daqueles que lidam com problemas de desenvolvimento em países subdesenvolvidos. Aqui também ocorre uma 
busca intensa de compreensão dos processos inovadores que poderiam contribuir para a superação desse estado de subdesenvolvimento. No entanto, existem certas características no funcionamento das economias subdesenvolvidas que colocam restrições aos processos inovadores, inexistentes nas situações estudadas pelos autores dos países desenvolvidos. Neste texto vamos discutir algumas delas e as implicações que trazem para o uso do conceito de Sistemas Regionais de Inovações. Também será apresentado o caso do estado do Paraná, no Brasil, e dentro dele, a experiência específica de uma empresa considerada modelo no que se refere à inovação tecnológica e interação com as organizações educacionais paranaenses: a Siemens/Equitel. Palavras-chave: Sistemas Regionais de Inovação, desenvolvimento regional, reestruturação produtiva, países subdesenvolvidos.

\begin{abstract}
The emphasis on innovations as responsible for the differences in performance of national and regional economies has been increasing in the economic literature. They appear as key element in several theories, such as evolutionary economics (LUNDVALL, 1922), the regulation theory (AMABLE et al. 1997), the industrial district approach (BECATTINI, 1991) and even in the neoclassical economy (ROMER, 1990). As the majority of this literature emphasizes the territorial aspects of this subject, regional policy-makers are putting their hopes in these themes as they used to do in the past about the growth pole theory. The same hopes are again up-to-date for those involved in development issues at the developing countries. There is an effort on research about innovative process that would be helpful for these countries. However, there are some restrictions in these innovative processes at developing countries that are not present in the reality studied by the authors of innovation theory. This paper examines some of these restrictions and the problem that they put for the concept of Regional Innovation System, being this discussion illustrated by the case study of Siemens/Equitel in Parana. Key-words: Regional Innovation System, regional development, economic change, developing countries.
\end{abstract}




\section{REFERÊNCIAS}

AMABLE, B.; BARRÉ, R.; BOYER, R. Les systèmes d'innovation à l'ère da la globalisation. Paris: Economica, 1997.

BECATTINI, G. The industrial district as a creative milieu. In: BENKO, G.; DUNFORD, M. Industrial Change and Regional Development. London: Pinter, 1991. p.102-114.

BOISIER, S. El difícil arte de hacer región: las regiones como actores territoriales del Nuevo Orden International. Cusco: Centro de Estudios Regionales Andinos Bartolomé de las Casas, 1992.

Política econômica, organização social e desenvolvimento regional. In: HADDAD, P. R.(Org.). Economia regional: teorias e métodos de análise. Fortaleza: BNB/Etene, 1989. p. 589-694.

BOUdEVILlE, J. Amenagement du Territoire et Polarisation. Paris: Génin, 1972.

CARLEIAL, L. M. F. Sistemas Regionais de Inovação (SRI) e relação entre firmas: as pistas para um formato de desenvolvimento regional. Revista Econômica do Nordeste, Fortaleza, v. 28, n. especial, p. 143-168, jul. 1997.

COOKE, P.; MORGAN, K. The Associational Economy: firms, regions and innovation. London: Oxford University Press, 1998a.

; BRACZYK, H. J.; HEIDENREICH, M. Regional Innovation Systems: the role of governances in a globalized world. London: UCL Press, $1998 \mathrm{~b}$.

; URANGA, M. G.; ETXEBARRIA, G. Regional Innovation Systems: institutional and organizational dimensions. Research Policy, n. 26, p. 475-491, 1997.

CORAGgIO, J. L.; On Social Spaceness And The Concept of Region. In: WORLD REGIONAL SCIENCE CONGRESS, 1., 1980, Cambridge, Mass. Mimeog.

GUIMARÃES NETO, L. Desigualdades regionais e federalismo. In: AFFONSO, R. B. A.; SILVA, P. L. B. (Org.). Desigualdades regionais e desenvolvimento. São Paulo: Fundap/ Unesp, 1995.

Dimensões, limites e implicações da desconcentração espacial no Brasil. Curitiba: Ilpes/Ipardes, 1996. (Mimeog.)

LUNDVALL, B. (Ed.). National Systems of Innovation: towards a theory of innovation and interactive learning. London: Pinter, 1992.

MAILLAT, D. Comportements spatiaux et milieux innovateurs. In: AURAY, J. P. et al. Encyclopédie d'économie spatiale. Paris: Economica, 1994. p. 255-262.

MARKUSEN, A. Regions: the economics and politics of territory. Totowa, NJ: Rowman and Littlefield, 1987.

METCALFE, J. S. Technology Systems and Technology Policy in an Evolutionary Framework. Cambridge Journal of Economics, v. 19, n. 1, p. 25-46, 1995.

PASSOS, C .A. K. Inovação tecnológica localizada: o caso do Paraná. Curitiba: Ed. Do Autor, 1998.

PORTER, M. The Competitive Advantage of Nations. New York: Free press, 1990.

PUTNAM, R. Making Democracy Work: civic traditions in modern Italy. Princeton: 
ROLIM, C. É possível a existência de sistemas...

Princeton University Press, 1992.

ROLIM, C. F. C. O Paraná urbano e o Paraná do agrobusiness: as dificuldades para a elaboração de um projeto político. Revista Paranaense de Desenvolvimento, Curitiba, v. 6, n. 86, p. 49-100, 1996.

O Estado do Iguaçu: tentativa de interpretação do regionalismo no Brasil Meridional. In: ENCONTRO NACIONAL DE ECONOMIA, 21., 1993, Belo Horizonte, Anpec.

ROMER, P. Endogenous Technological Change. Journal of Political Economy, n. 98, p. 70-102, 1990.

SCATOLIN, F. et al. Sistemas regionais de inovação: o caso da Siemens Telecomunicações do Paraná. Curitiba: Departamento de Economia, Universidade Federal do Paraná.CNPq, 1999.

VELTZ, P. Mondialisation, Villes et Territoire: l'économie d'archipel. Paris: PUF, 1996.

ZARIFIAN, P. L'attrait du modèle japonais et sa relativité. In: HIRATA, Helena. (Dir.). Autour du modèle "japonais". Paris: L'Harmattan, janvier 1993. 